\title{
Modelagem na educação matemática: contribuições da teoria a prática
}

\author{
Modeling in mathematical education: contributions from \\ theory to practice
}

\section{Modelado en educación matemática: contribuciones de la teoría a la práctica}

\author{
Marcelo Navarro Da Silva \\ Secretaria Estadual de Educação de SP \\ São Paulo , Brasil, \\ E-mail:marcelnava@yahoo.com.br \\ Orcid:0000-0001-9039-8937 \\ Simone Bueno \\ Secretaria Estadual de Educação de SP \\ São Paulo, Brasil \\ E-mail:Simbue123@hotmail.com \\ Orcid:0000-0002-8115-0005
}

Resumo: Este artigo tem como objetivo mostrar a relação entre a Modelagem Matemática e exemplos de atividades práticas desenvolvidas em sala de aula. Acredita- se que o potencial da Modelagem pode auxiliar no desenvolvimento da aprendizagem dos estudantes e permitindo ainda a reflexão dos docentes nas ações de seu planejamento. Apresenta-se teóricos da Modelagem Matemática: Bassanezi, Barbosa e Davis e Hersh entre outros, que caracterizam a área de estudo e permitem maiores reflexões sobre o assunto. Demonstra-se que algumas atividades que foram desenvolvidas no $9^{\circ}$ ano do Ensino Fundamental. Correlaciona-se a teoria com as atividades e concluímos que as atividades desenvolvidas na Modelagem Matemática estimulam os estudantes em suas aprendizagens, assim como auxiliam no planejamento do professor. Identifica-se ainda que a Modelagem Matemática permite diálogos entre os diferentes saberes, e interlocutores do processo de ensino e aprendizagem. E por fim, conclui-se que a pesquisa dessa grandeza deve ser utilizada nos processos de formação de professores. 
Palavras-chave: Modelagem Matemática. Educação Matemática. Formação de Professores.

Abstract This article aims to show the relationship between mathematical modeling and examples of practical activities developed in the classroom. It is believed that the potential of Modeling can aid in the development of students' learning and also allows the reflection of the teachers in the actions of their planning. Mathematical Modeling theorists are presented: Bassanezi, Barbosa and Davis and Hersh among others, that characterize the area of study and allow greater reflections on the subject. It is demonstrated that some activities that were developed in the 9th grade of Elementary School. The theory is correlated with the activities and we conclude that the activities developed in Mathematical Modeling stimulate the students in their learning, as well as help in the planning of the teacher. It is also identified that Mathematical Modeling allows dialogues between different knowledge, and interlocutors of the teaching and learning process. And finally, it is concluded that the research of this greatness must be used in the processes of teacher training.

Keywords: Mathematical Modeling. Mathematics Education. Teacher Training.

Resumen: Este artículo tiene como objetivo mostrar la relación entre el Modelado Matemático y ejemplos de actividades prácticas desarrolladas en el aula. Se cree que el potencial del Modelado puede ayudar en el desarrollo del aprendizaje de los estudiantes y también permitir la reflexión de los docentes en las acciones de su planificación. Se presentan teóricos del Modelado Matemático: Bassanezi, Barbosa y Davis y Hersh, entre otros, quienes caracterizan el área de estudio y permiten mayores reflexiones sobre el tema. Se muestra que algunas actividades que se desarrollaron en el 9ำ año de Educación Primaria. La teoría se correlaciona con las actividades y se concluye que las actividades desarrolladas en Modelado Matemático estimulan a los estudiantes en su aprendizaje, además de ayudar en la planificación del docente. También se identifica que el Modelado Matemático permite el diálogo entre los diferentes saberes e interlocutores del proceso de enseñanza y aprendizaje. Y finalmente, se concluye que investigaciones de esta magnitud deben utilizarse en los procesos de formación docente.

Palabras clave: Modelización matemática. Educación matemática. Formación del profesorado.

Recebido em

06/04/2020

Aceito em

12/05/2020 


\section{CONSIDERAÇÕES INICIAIS}

A Matemática ao longo do tempo vem constituindo com um campo de muitas descobertas e modificações na construção de saberes. Neste avanço surgiram dificuldades quanto ao seu ensino, como também à aprendizagem.

Observamos nos dias atuais a existência de dificuldades dos estudantes ao compreenderem o papel social da Matemática em suas atividades. Tal fato acarreta certo desinteresse pela Matemática, que é evidenciado em pesquisas como Ponte (1994), Carvalho, Miguel, Mendes e Brito (1998), Bitencourt e Batista (2009) concernem que: "Um dos obstáculos imediatos do sucesso do ensino e aprendizagem da Matemática diz respeito ao desinteresse dos estudantes com relação ao modo como a Matemática é apresentada em sala de aula" (Carvalho, Miguel, Mendes e Brito, 1998, p.108).

Acreditamos que a Modelagem Matemática pode contribuir significativamente nas ações de planejamento do docente e por consequência no entendimento e aprendizagem dos estudantes (Bueno, Alencar e Gomes, 2016).

Todavia, ao realizar a Modelagem Matemática é interessante procurar caminhos que sejam adequados para que se possa atingir objetivos, ou seja, tenha utilidade para as ações do sujeito. Este fato promoverá uma melhor compreensão dos conceitos matemáticos.

A Modelagem Matemática favorece momentos que possibilitam aflorar o interesse dos estudantes e oportunizam momentos interessantes para estabelecer relações entre a matemática que se aprende na escola e seu possível uso no cotidiano.

Nesse contexto, consideramos que a Modelagem Matemática é uma metodologia relevante a ser considerada no âmbito escolar para a construção e elaboração de objetos de conhecimentos matemáticos, lembrando que muitas vezes os estudantes já possuem os conceitos de modo informal e a Modelagem possibilita momentos que 
corroboram para o entendimento de forma sistêmica, desde os anos iniciais do Ensino Fundamental, prosseguindo até o Ensino Médio.

Desse modo, a Modelagem Matemática pode contribuir significativamente nas ações de planejamento do docente e, por consequência, no entendimento e aprendizado.

Nosso objetivo com esse estudo foi demonstrar de modo prático e experimental como a Modelagem Matemática pode contribuir no processo da aprendizagem dos estudantes. Além disso, refletir como o docente pode planejar suas ações nesses moldes. Para isso apresentamos três atividades desenvolvidas com estudantes do Ensino Fundamental para que possamos refletir sobre as potencialidades da Modelagem como ação pedagógica.

\section{MAS AFInAL, O QUE É MOdELAGEM MATEMÁticA?}

A modelagem matemática começou a iniciar suas discussões como temática da área da Educação Matemática no final dos anos 1970 e 1980 quando alguns pesquisadores começaram a participar de eventos internacionais que já abordavam este tema. Entre eles: Aristides C. Barreto, Ubiratan D’ambrosio, Rodney C. Bassanezi, João Frederico Mayer, Marineuza Gazzetta e Eduardo Sebastiani Ferreira. Posteriormente no final dos anos 90 começou o interesse das universidades em integrar a Modelagem Matemática em seu currículo. Esse movimento fez com que aumentasse 0 interesse dos professores pelo assunto, assim como houve crescimento de relatos e pesquisas nesse sentido. Os interesses nessa área de pesquisa foram aumentando e demostramos alguns dos pesquisadores que se aprofundaram nesse contexto.

D’ambrosio (1999) relata que a dialética entre teoria e a pratica envolvendo contextos da etnomatemática e utilizando-se dos princípios socioculturais, deve ser incentivado por meio da modelagem. Para o autor a Modelagem Matemática utiliza da realidade social e cultural para realizar modelos matemáticos e em anos posteriores, definiu a Modelagem como: "um processo muito rico de encarar situações e culmina 


\section{Universidade Federal da Grande Dourados}

com a solução efetiva do problema real e não com a simples resolução formal de um problema artificial." (D’ambrosio, 1986, p115)

Já Barreto (1971) defendia o uso da Modelagem Matemática no ensino desde meados dos anos 70, no qual caracterizava seu uso nas disciplinas de cálculo das engenharias (Silva, 2009). Para Gazzeta (1989) havia-se um distanciamento entre os modelos e o ensino e este foi adotado a partir do século XIX por diferentes pesquisadores e autores, e assim tornou - se assunto de pesquisa Matemática e metodologia para o ensino e aprendizagem de matemática. Bassanezi nos diz que a modelagem Matemática vem se delineando ao longo do tempo e que sua caracterização pode ser constituída em dois modos:

Neste sentido, de acordo com Bassanezi (1999), em relação as aplicações da Matemática, duas alternativas mostram-se bem delineadas: uma primeira visão consiste em adaptar conceitos, configurações ou estruturas matemáticas aos fenômenos da realidade - muitas vezes, sujeitando aspectos da realidade, físicosociais e outros, a tender da melhor maneira possível aos modelos matemáticos que Ihes são atribuídos. Numa segunda alternativa temos situações a realidade servindo como fonte para a obtenção de novos conceitos e estruturas matemáticas - com efeito, neste sentido, os paradigmas da construção cientıfica, já estabelecidos, dão lugar a novos paradigmas e a Matemática evolui como um retrato do universo. "Talvez, seja esta visão, próxima de uma explicação platônica sobre o desenvolvimento da Matemática, a razão da existência e funcionalidade da Matemática." (Bassanezi,1999,p11-12)

Neste sentido, a Modelagem Matemática trata-se de um processo ou assim como autor chama "uma ação pedagógica" dinâmica que possibilita buscas a modelos que sirvam para explicar determinado fenômeno. O autor define que "A modelagem matemática consiste essencialmente na arte de transformar problemas da realidade e resolve-los, interpretando suas soluções na linguagem do mundo real" (Bassanezi, 2002, p.34). 


\section{Universidade Federal da Grande Dourados}

Bassanezi (1994) acrescenta ainda que existem cinco motivos significativos para a inclusão da Modelagem Matemática no currículo como: a motivação, a possibilidade para atingir a aprendizagem, a utilização da Matemática em diferentes contextos e áreas, e a reflexão e desenvolvimento para a compreensão de aspectos socioculturais (Bueno, Alencar e Gomes, 2016). Nesses moldes, Bassanezi acrescenta que a Modelagem Matemática se utiliza de uma porção da realidade para pensar e agir sobre ela.

Barbosa (2001) acrescenta que a Modelagem Matemática tem como objetivo "potencializar a intervenção de pessoas nos debates e nas tomadas de decisões que envolvam aplicações de Matemática" (Barbosa, 2001, p.74). Acredita-se ainda que essas ações têm amplitude de construir e consolidar as sociedades democráticas, pois ao trabalhar com atividades que envolvem a Modelagem Matemática, essas levam os estudantes a se apropriarem do papel sociocultural da matemática e este fato os incentiva a aprender e adquirir fascínio pelos conhecimentos Matemáticos. Para o autor a Modelagem Matemática é:

Problematização e investigação. O primeiro refere-se ao ato de criar perguntas e/ou problemas enquanto que o segundo, à busca, seleção, organização e manipulação de informações e reflexão sobre elas. Ambas atividades não são separadas, mas articuladas no processo de envolvimento dos alunos para abordar a atividade proposta. Nela, podem-se levantar questões e realizar investigações que atingem o âmbito do conhecimento reflexivo. (Barbosa, 1999, p. 75)

Davis e Hersh (1986) nos dizem que a modelagem pode ser considerada boa, ruim, simples e satisfatória, estética ou feia, útil ou inútil, sendo difícil ver sua veracidade.

Verificamos que os aspectos de utilidade têm como potencial satisfazer a necessidade humana. Ressaltamos ainda que a questão de utilidade da Matemática tem sido muito discutida, pois depende do olhar de cada Matemático. Com isso, devese sempre ao realizar a Modelagem Matemática procurar caminhos que sejam adequados para que se possa atingir objetivos, ou seja, tenha utilidade para as ações do sujeito. Este fato promoverá uma melhor compreensão dos conceitos matemáticos. 
Toledo, Meyer e Filho caracterizam a Modelagem Matemática como:

Simulação de processos permite que algumas das etapas do processo de domínio tecnológico sejam realizadas de modo rápido e econômico. O resultado do trabalho de modelagem é um programa computacional que serve de base, quando validado adequadamente, para novos estudos e otimização, controle e projeto. (Toledo, E. C. V., Meyer J. F. C. A., Filho, R. B, 2005, p.2)

Ferreira (1994) nos diz que a Matemática está modificando o modo como vem sendo percebida pela sociedade. Tal fato é apontado pelo autor, Zufliga apud Ferreira (1994) em conferencias proferida em "Las Matemáticas Modernas en las Américas: filosofia de una reforma" no VIII CIAEM, Miami, USA.

A natureza da Matemática está mudando: há muitos indícios disto. Cada dia, mais pessoas questionam o modelo de Matemática infalível, absoluto, longe da intuição empírica e da realizada terrena, que dominou até agora urbi et orbi. Cada vez se percebe melhor a íntima relação entre as matemáticas e a sociedade. Cada vez tem-se mais espaços para um novo paradigma sobre a natureza das matemáticas, um paradigma empírico e construtivista, um paradigma que recorre à intuição sensorial, um paradigma que integre no seu seio as influências sociais e culturais, que recorre à História das Matemáticas e das Ciências como inspiração, não só para anedotas, senão para estabelecer a lógica que sustenta a prática educativa de uma forma mais acertada. (Ferreira, E. S.,1994) .

Nesta interlocução Ferreira (1994) ressalta que a Modelagem Matemática em seu ponto de vista é uma mistura de conhecimento especifico da realidade, conhecimentos básicos, meios de comunicação e saber fazer, correlacionados com as abstrações que envolvem estratégias e técnicas de ação.

Acrescentamos ainda que Maturana e Varela (1995) entendem que a Modelagem Matemática deve ter: fenômeno a ser explicado, hipótese explicativa, dedução de outros fenômenos, informações e observações adicionais. Os autores salientam que o processo de Modelagem Matemática é interdisciplinar e pode ser utilizado em vários campos do conhecimento.

Já Burak e Klüber (2008) entendem que a Modelagem Matemática deve estar relacionada com situações da sala de aula, e esta relação deve ocorrer entre teoria e 
prática. O autor apresenta cinco etapas para o desenvolvimento de Modelagem em Matemática: $1^{\circ}$ Escolha do tema, $2^{\circ}$ Pesquisa exploratória, $3^{\circ}$ Levantamento de problemas, $4^{\circ}$ Resolução dos problemas, $5^{\circ}$ Analise Crítica das soluções.

Biembengut (1999) ressalta que a modelagem matemática pode incentivar o estudante a aprender matemática, de modo que resolva situações aprendendo "modelar matematicamente" (p.23). Para ela um modelo:

A noção de modelo se faz presente em todas as áreas. Grosso modo, um modelo é um conjunto de símbolos os quais interagem entre si representando alguma coisa. Esta representação pode se dar por meio de um desenho ou imagem, um projeto, um esquema, um gráfico, uma lei matemática, dentre outras formas. Na matemática, por exemplo, "um modelo é um conjunto de símbolos e relações matemáticas que traduzem, de alguma forma, um fenômeno em questão" (Biembengut, 1999, p.20).

Neste contexto a Modelagem Matemática para Biembengut é "um conjunto de procedimentos requeridos na feitura de um modelo" (p.21). A autora acrescenta que:

Pode ser considerado um processo artístico, visto que, para se elaborar um modelo, além de conhecimento de matemática, o modelador, precisa ter uma dose significativa de intuição e criatividade para interpretar o contexto, saber discernir que conteúdo matemático melhor se adapta e também ter senso lúdico para jogar com as variáveis envolvidas. (Biembengut, 1999, p.21)

Verificamos um aspecto da Modelagem Matemática que é advertido por Hermínio e Borba (2010) apresentando a diversidade de caracterizações sobre essa temática. Percebemos tal fato na assertiva:

E possível notar que não há uma única definição para este conceito. Ao contrário, é fácil se deparar com diferentes concepções desta tendência na Educação Matemática. Embora não haja um consenso quanto à sua definição, concepções semelhantes de Modelagem Matemática podem ser agrupadas de acordo com suas características. (Hermínio e Borba, 2010 p.111)

Por este motivo consideramos necessário apresentar argumentações de alguns dos autores que pesquisam sobre a Modelagem Matemática, para embasarmos nossos exemplos de atividades práticas desenvolvidas em sala de aula. 


\section{Universidade Federal da Grande Dourados}

A importância de trabalhar com atividades de Modelagem Matemática em sala de aula

No trabalho de Silva (2009) encontramos a importância de desenvolver atividades de Modelagem Matemática em diversos níveis educacionais. $\mathrm{O}$ autor traz relatos de pesquisas que enfatizam contribuição nesse seguimento, (Santos \& Bisognin, 2007), (Ferreira e Wodewotzki, 2007), (Friedmann e Lozano, 2007), (Santana, 2007) e (Grandsard e Schatterman, 1989).

No trabalho de Santos e Bisognin (2007) é relatado uma atividade com estudantes do Ensino Fundamental dos anos Finais em que a temática para abordagem da Modelagem Matemática é Poluição do ar, do solo e das águas, temática que suscitou discussões que partiram de dados reais, promoveram o desenvolvimento de conceitos matemáticos tais como Funções e Estatística. Para as autoras, a abordagem da Modelagem em sala de aula possibilitou um trabalho de investigação de forma participativa e colaborativa e para os professores a experiência de um novo fazer pedagógico (Silva, 2009)

Ferreira e Wodewotzki (2007) mencionam em sua pesquisa a experiência com estudantes de uma escola pública do município de Rio Claro no Estado de São Paulo. Os mesmos elaboram modelos matemáticos com base nas questões ambientais como água, lixo, energia e desmatamento. Nas considerações das autoras, tais atividades encorajaram os estudantes a vislumbrarem a Matemática como um instrumento de análise e interpretação da realidade, e salientam que as atividades de Modelagem não são como um instrumento de aplicação, mas como um processo de investigação de outras áreas do conhecimento (Silva, 2009). O trabalho de Friedmann e Lozano (2007) tem como destaque a utilização da teoria dos grafos em atividades de Modelagem no curso de licenciatura em Matemática da Universidade do Estado do Rio de Janeiro. Os autores enfatizam em sua pesquisa que é necessário um investimento em trabalhos voltados para exercícios de forma algorítmica de resolver problemas. Eles comentam que o algoritmo é uma parte importante na Modelagem em certos problemas que dispõem de um método que garanta uma melhor resposta (Silva, 2009). 


\section{Universidade Federal da Grande Dourados}

Sant Ana (2007) relata uma experiência de Modelagem em uma aula de cálculo do curso de Engenharia Mecânica da Universidade Luterana do Brasil. A autora destaca que os programas das Universidades estão pré-estabelecidos a serem cumpridos, mas é possível concomitantemente realizar atividades de Modelagem nas disciplinas de Cálculo e outras, sem que se comprometa o cumprimento do programa (Silva, 2009).

Sob uma perspectiva internacional, Booth (1989) argumenta as atividades de crianças diante de uma pintura. A pesquisa mostra a relação natural entre o padrão da pintura espontânea e a transformação geométrica, e segundo sua pesquisa, os conceitos matemáticos podem ser trabalhos de forma intuitiva na perspectiva das pinturas (Silva, 2009). Booth argumenta que o padrão das pinturas exibe uma rica fonte de arte intuitiva em conceitos matemáticos que pode ser usada como ponto de partida para discussões, e que é um excelente caminho para ensinar matemática em um contexto real como o da criatividade infantil (Silva, 2009).

Grandsard e Schatteman (1989) relatam a observação de um curso de resolução de problemas com estudantes universitários em que os autores ministraram. Suas considerações revelaram claros indícios de que os estudantes participantes do curso tiveram um desempenho satisfatório (Silva, 2009). O curso de Grandsard e Schatteman abordou uma estratégia de resolução em que se obedece aos processos de análise, planejamento, exploração, implementação e verificação

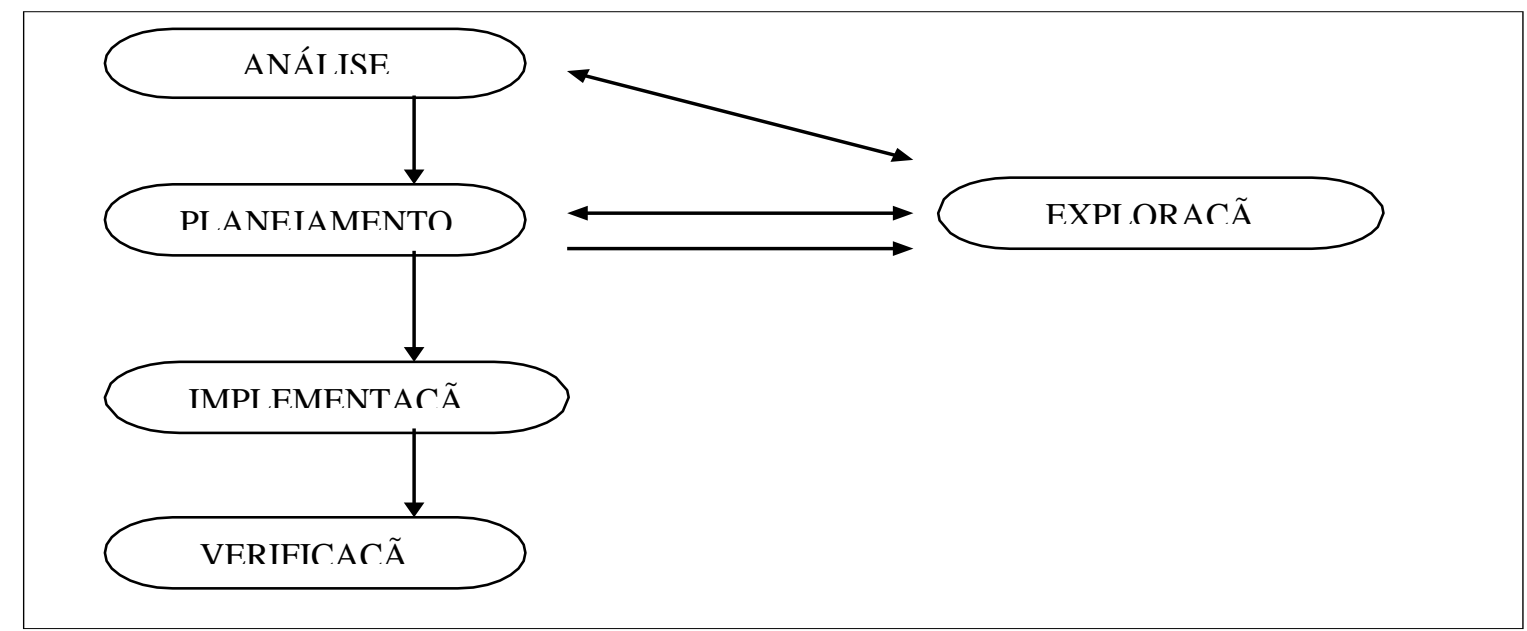


Figura 1: fluxograma proposto por Grandsard e Schatteman (1989)

Observando o fluxograma proposto por Grandsard e Schatteman no momento da análise o estudante tende a familiarizar-se com o problema, e na etapa do planejamento ele tenta resolver o problema utilizando uma estratégia. Nessas duas etapas há um processo de exploração em que a mobilização de conhecimentos prévios, métodos de provas ou equivalentes tornam o acesso ao problema mais fácil. Depois de elaborado um plano, ele deverá ser implementado e a verificação de sua solução deve ser de acordo com o modelo encontrado ou elaborado (Silva, 2009).

Grandsard e Schatteman (1989) salientam que o fluxograma não deve ser interpretado como um programa em que os estudantes supostamente deverão aplicar automaticamente na resolução de problemas, mas poderá ser um guia caso os estudantes não consigam resolver o problema.

Elaboração das atividades: procedimento de pesquisa

Para uma melhor compreensão do conceito da Modelagem Matemática apresentamos três atividades que foram desenvolvidas com estudantes da Educação Básica da rede pública de ensino do Estado de São Paulo, mas especificamente no Ensino Fundamental séries finais.

A primeira atividade foi desenvolvida com estudantes do $9^{\circ}$ ano do ensino fundamental II, da Educação de Jovens e Adultos (EJA). Para a realização da atividade foram utilizadas dez aulas, mas o número de aulas pode variar para mais ou para menos, dependendo da dinâmica de cada aula ou ritmo dos estudantes. $\mathrm{O}$ objetivo dessa atividade era que os estudantes, por meio de estratégias próprias, medissem o comprimento da circunferência, do diâmetro, calculassem a razão entre eles e após descobrissem a presença do número $\pi$.

A segunda atividade foi desenvolvida em outra unidade escolar, com estudantes do 9 o ano do ensino fundamental séries finais, ensino regular, e para essa atividade foram utilizadas oito aulas. Por meio dessa atividade, eles puderam construir um Tangram, montar, reconhecer e identificar figuras planas, calcular a área e o 


\section{Universidade Federal da Grande Dourados}

perímetro, além de entender que figuras com a mesma área podem ter perímetros diferentes.

A terceira atividade foi trabalhada com outra turma do 9 a ano do ensino fundamental II, ensino regular, da mesma escola que foi proposta a segunda atividade. Por meio dessa atividade os estudantes puderam calcular a área de figuras planas e identificar as frações relacionadas à figura.

Atividade 1 - Descobrindo a presença do número $\pi$.

Material utilizado: Objetos de base circular, Instrumentos de medida, Calculadora e Folha quadriculada

\section{Etapa 1 - Coleta dos dados}

A aula inicia-se com a professora explicando que, a partir daquela aula, estariam desenvolvendo uma atividade relacionada ao número $\pi$. Coloca sobre a mesa uma caixa de papelão com alguns objetos "redondos". Os estudantes ficam aguçados olhando os objetos e curiosos para saber o que estariam fazendo com aquele material. A professora coloca uma mesa no centro da sala e começa a dispor alguns objetos sobre ela, tais como: disco de vinil, CD, tubinho do rolo de papel higiênico, frasco de remédio, tampa de objetos diversos, cano de PVC.

À medida que dispõe os objetos sobre a mesa, aproveita para questionar os estudantes: Ao observar esses objetos o que vocês percebem? Que tipo de forma tem esses objetos? Aqui na sala de aula, olhando ao nosso redor, onde podemos encontrar objetos com essas formas? O que caracteriza as formas desses objetos? A medida que a professora questiona, os estudantes respondem.

A professora pede para cada aluno pegar um objeto na caixa, desenhar no caderno o objeto escolhido, medir o diâmetro e a circunferência, e depois trocarem o objeto com os colegas de sala, até todos usarem os objetos escolhidos por cada um, desenhado e medido no caderno. Depois que todos tivessem concluído as medições, os dados seriam colocados na lousa. 


\section{Universidade Federal da Grande Dourados}

Todos se dirigem à caixa e escolhem um objeto. Nesse momento, observamos um clima de total interação na sala, tanto no que diz respeito aos estudantes entre si como entre a professora e os estudantes. A professora se movimenta na sala durante todo o tempo em que os eles realizam a medição, auxiliando-os em suas dificuldades.

Após os estudantes realizarem as medidas e anotarem os dados no caderno, a professora propõe que os dados sejam dispostos em uma tabela. Desenha uma tabela na lousa e mostra o modo como deveriam dispor seus dados. Na tabela, deveria constar o valor do diâmetro, representado pela letra D, o valor da circunferência, representado pela letra $\mathrm{C}$, e a razão entre o diâmetro e a circunferência, representado por $\mathrm{C} / \mathrm{D}$, e estes deveriam utilizar como unidade padrão de medida o centímetro.

\section{Etapa 2 - Análise dos Dados}

Nessa etapa os dados coletados individualmente foram socializados e organizados em uma tabela na lousa, em ordem crescente, para que todos os estudantes pudessem visualizar o valor encontrado na medição de cada objeto, contendo o valor encontrado do diâmetro, o valor da circunferência e a razão entre eles. Essa socialização foi importante, pois nesse momento eles puderam verificar que os dados do diâmetro variavam, o que chama a atenção sobre a discussão sobre os erros na medida. Também foi um momento oportuno para se discutir a possível relação entre diâmetro e o perímetro da circunferência.

\section{Etapa 3 - Análise dos resultados}

Após colocarem os dados coletados na tabela a professora solicitou que construíssem um gráfico no plano cartesiano. No eixo das abscissas foram colocados os valores do diâmetro e no eixo das ordenadas os valores da circunferência.

Nesse momento da atividade a professora aproveita para questionar os estudantes. O que é um gráfico no plano cartesiano?

Os estudantes observam, mas não respondem. Então a professora explica as características de um gráfico cartesiano, ou seja, que é uma reta orientada dos valores menores para os valores maiores e que eles se cruzam no centro do plano cartesiano, 


\section{Universidade Federal da Grande Dourados}

chamada origem, onde os valores abaixo do zero são os valores negativos e os valores acima do zero são os valores positivos. Explica também que, no eixo horizontal, os valores antes do zero são os negativos e após o zero são os valores positivos, e têm um nome esses eixos, o eixo horizontal é chamado de abscissa e também conhecido como eixo $\mathrm{x}$, onde no caso estariam colocando os valores do diâmetro.

O eixo vertical é chamamos de eixo das ordenadas, também conhecido como eixo y, onde seriam colocados os valores da circunferência, e os valores do diâmetro seriam colocados na abscissa. Então, por exemplo, se eu tenho um valor para $\mathrm{x}=1 \mathrm{e}$ a ele vai corresponder um valor $y=4$. Associando esses valores, no caso $(1,4)$, esse par de números que um corresponde ao outro é chamado de coordenada.

A professora aproveita esse momento, para fazer uma analogia com o jogo da batalha naval:

- Sabe aquela história da batalha naval que você localiza um ponto que vai ser atingido. No nosso caso, o mar seria o plano, e nesse sistema de eixos você vai localizar os alvos. Nesse caso se o submarino da batalha naval estiver localizado aqui no nosso plano cartesiano, como é que você vai especificar a localização deles? Você vai dizer o valor da coordenada dele, no caso 1 e 4.

- Outra coisa, se pensarmos no plano como um todo, os dois eixos que se cruzam na origem dividem o espaço em quatro partes e cada uma dessas partes é chamada de quadrante. Aqui temos o $1^{\circ}$ quadrante. Onde vocês acham que está o $2^{\circ}$ quadrante? Onde vocês colocariam o $2^{\circ}$ quadrante?

Eles olham e cada um aponta onde colocaria o $2^{\circ}$ quadrante. A professora explica que a ordem dos quadrantes obedece ao sentido horário.

- Pensem no ponteiro do relógio, ele gira no sentido horário (gesticula com as mãos para os estudantes, mostrando como é o sentido horário). Como seria o sentido anti-horário?

- O contrário. (Alguns estudantes gesticulam com as mãos). 
- Então, o sentido para dar nome ao quadrante é o sentido anti-horário, ou seja, contrário ao giro dos ponteiros do relógio. No nosso gráfico vamos trabalhar com o quadrante que tem os valores de $\mathrm{x}$ e de y positivos, porque $\mathrm{o}$ diâmetro e $\mathrm{o}$ comprimento da circunferência são medidas positivas.

Ao fazer uma analogia do plano cartesiano com regras do jogo da batalha naval, explicar o sentido anti-horário, utilizando como exemplo os ponteiros do relógio, a professora possibilita que o aluno utilize os conceitos matemáticos para compreender e fazer analogias com fatos presentes no seu mundo.

A professora pega uma folha quadriculada e pede para que os estudantes façam o mesmo, para que verifiquem o modo como irão colocar os dados na folha. Explica que, na vertical serão colocados os dados do comprimento da circunferência e na horizontal os valores do diâmetro. Explica também que a cada dois quadradinhos, que, na verdade, é um centímetro, estariam colocando os valores do diâmetro e da circunferência. Explica que essa é uma sugestão de escala, mas que cada aluno poderia fazer de outro modo também.

Após a construção do gráfico na folha quadriculada, os estudantes colam no caderno e procedem à discussão sobre os valores encontrados, e desse modo transpõem para um contexto prático o comprimento da circunferência, do diâmetro, e após descobrem a presença do número $\pi$.

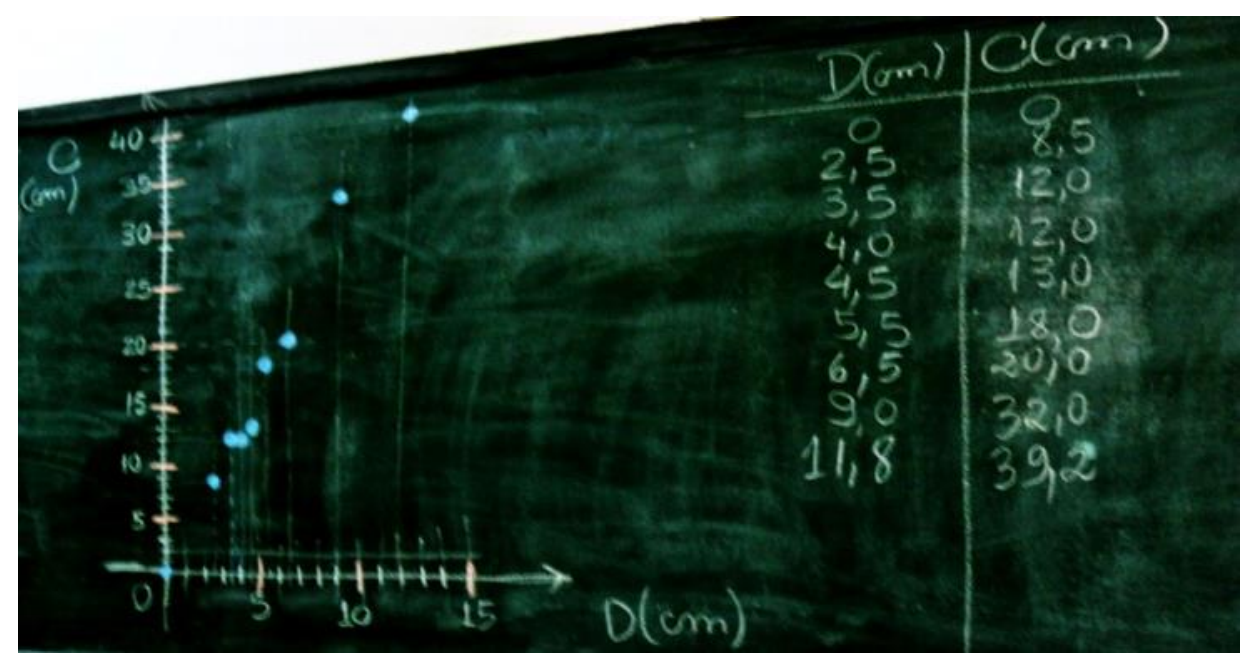

Figura 2: Tabela e gráfico com os valores do diâmetro e da circunferência 
Atividade 2 - Construindo Tangram.

Material utilizado: Régua, Lápis de cor, Folha de almaço e Folha quadriculada.

Etapa 1 - Construindo o Tangram

A aula inicia-se com a professora explicando que na aula estariam construindo um Tangram. Explica que seria uma espécie de quebra - cabeça formado por 7 peças (5 triângulos, 1 quadrado e 1 paralelogramo) e com estas peças eles poderiam formar várias figuras.

A professora explicita que gosta de trabalhar essa atividade de construção de Tangram, pois acredita que funciona como um facilitador para os estudantes compreenderem alguns conceitos de geometria, além de desenvolver a criatividade, raciocínio e a interação.

No primeiro momento da atividade, a professora solicita aos estudantes, com a utilização de uma régua, construam 10 modelos de Tangram em uma folha quadriculada. Cada Tangram deve ter medida de $12 \mathrm{~cm}$ por $12 \mathrm{~cm}$, formando assim um quadrado.

Após a construção do Tangram na folha quadriculada, cada aluno pinta com cores diferenciadas o Tangram construído. Essa diferenciação nas cores é importante para uma melhor visualização de cada figura que compõe o Tangram.

No próximo momento, com o auxílio de uma tesoura, eles recortam as peças do Tangram.

Etapa 2 - Formando figuras

Com as peças recortadas, a professora solicita para que formem triângulos utilizando três, quatro, cinco e sete peças respectivamente e colem na folha de almaço. 


\section{Universidade Federal da Grande Dourados}

Solicita para que os estudantes formem alguns quadrados também. A professora informa que na montagem dos quadrados seja utilizada uma, duas, três, quatro, cinco, sete peças.

\section{Etapa 3 - Calculando áreas}

Na próxima etapa, a professora pede para os estudantes calcularem a área de cada figura montada assim como o perímetro dessas figuras.

Nesse momento a professora questiona-os:

- Será que as figuras com a mesma área possuem sempre o mesmo perímetro? Os estudantes com a manipulação das figuras geométricas, construídas por eles, calculam os valores pedidos, socializam os valores encontrados e por meio de suas constatações verificam que figuras com a mesma área podem ter perímetros diferentes.

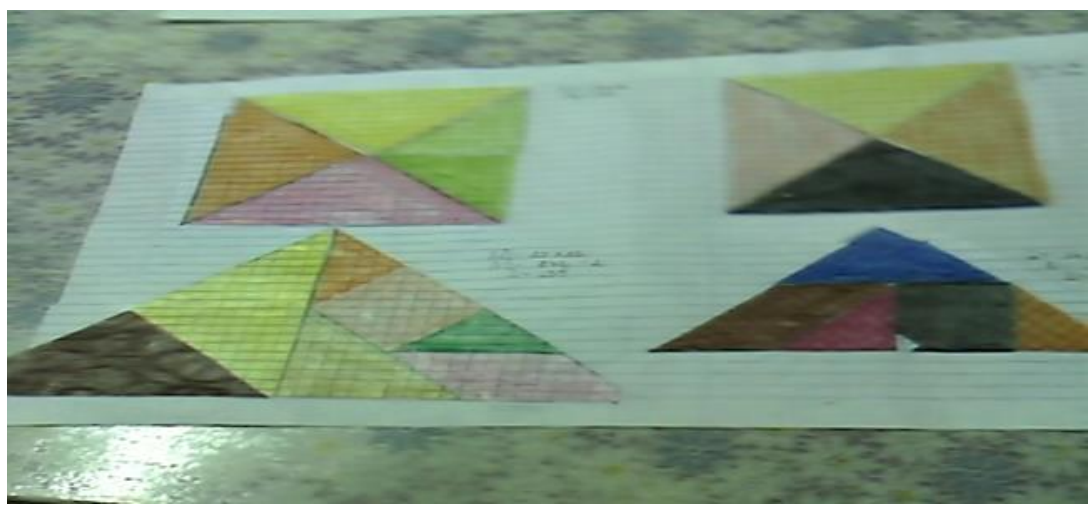

Figura. 3: Triângulos e quadrados construídos

\section{Atividade 3}

Material utilizado: Régua, Lápis de cor e Folha quadriculada

A professora inicia a aula explicando aos estudantes que na aula estaria desenvolvendo uma atividade para calcular a área de figuras planas e identificar as frações relacionadas à figura, distribuindo para cada estudante a planta de um apartamento. Distribui uma folha de papel quadriculado para cada estudante e solicita 


\section{Universidade Federal da Grande Dourados}

para que represente essa planta na folha. Explica que nesse esquema cada quadradinho corresponde a $1 \mathrm{~m}^{2} \mathrm{da}$ área do apartamento.

À medida que eles vão representando na folha de papel quadriculado, a professora circula pela sala auxiliando-os. Assim que todos terminam suas representações a professora questiona:

- Que fração da área do apartamento corresponde ao banheiro?

- Qual a área de cada cômodo do apartamento?

- Qual a área total do apartamento?

Na realização dessa atividade podemos destacar a interação dos estudantes, o que contribui com a aprendizagem. O desenho da planta do apartamento na folha quadriculada facilita a compreensão do cálculo de área, perímetro e a representação de frações de acordo com os cômodos analisados. No início os eles tiveram algumas dificuldades no tocante a representação das frações contidas no problema, mas por meio das intervenções pontuais da professora puderam sanar suas dúvidas e entenderam como iriam representar as frações. 


\section{CONSIDERAÇÕES FINAIS}

Essas atividades demonstram ser estimuladoras ao desenvolvimento das aprendizagens dos discentes, pois traz uma nova postura em relação ao entendimento dos conteúdos matemáticos. A modelagem pode ser trabalhada em todos os segmentos de ensino, tanto no Ensino Regular como da Educação de Jovens e Adultos, demonstrando assim sua transdisciplinaridade, pois possibilita aos estudantes mobilizarem saberes, fazerem pesquisas, deduções e chegarem a conclusões a partir de estratégias próprias. Utilizamos aqui o conceito de transversalidade como o citado por Burak e Klüber (2008) que com a utilização da Modelagem Matemática esta promove uma visão de totalidade dos saberes, permitindo interrelações entre os participantes do processo de ensino aprendizagem a teoria e a prática.

Tais considerações são evidenciadas na atividade 1, na qual os estudantes mediram utilizando estratégias próprias os objetos e construíram cada qual a sua tabela, procederam a construção do gráfico, fazendo deduções e socializando os resultados encontrados.

Já o modo como a professora conduziu a atividade 2 possibilitou aos estudantes observarem e identificarem nas peças do Tangram as figuras da geometria plana, entendendo na prática que figuras com a mesma área nem sempre tem o mesmo perímetro.

A atividade 3 possibilitou a resolver problemas envolvendo o cálculo de cálculo de área de figuras planas.

Consideramos que no percurso curricular não há como prever qual caminho será o mais fácil, ou qual caminho será o mais interessante, pois na medida em que o professor elabora a atividade, é na interação que acontece com os estudantes que ele 


\section{Universidade Federal da Grande Dourados}

percebe em quais momentos eles terão mais dúvidas, dificuldades, e assim, o mesmo irá fazer as intervenções necessárias e acreditar que essa interação é de suma importância para que ocorra o sucesso no processo ensino aprendizagem.

O papel do diálogo é citado como consideração relevante na pesquisa de Malheiros (2008) que em sua tese analisou as diferentes interfaces de projetos de modelagem em Educação a Distância. Em outro estudo recente Tortola (2012) realizou uma dissertação baseada nos estudos de Wittgenstein. Nesta percebe-se que o uso de diferentes linguagens em diferentes contextos que contribuem para que haja um melhor entendimento dos conteúdos matemáticos desenvolvidos em atividades de Modelagem.

Além disso, notamos que três dos autores citados, Bassanezi (1994) Barbosa (2001) e Biembengut (1999) ressaltam que a modelagem matemática é um dos possíveis caminhos para o desenvolvimento de conhecimentos matemáticos de modo construtivo, fazendo com que o estudante se interesse mais pela a Matemática e a compreenda o seu por que e para que? Neste sentido está se torna uma motivação para os aspectos curriculares desempenando melhorias socioculturais.

Acreditamos que os estudos teóricos e as pesquisas são fundamentais para que o professor possa situar-se de uma maneira crítica conhecendo as metodologias atuais e as que tiveram práticas exitosas para melhor poder atender seus estudantes, pois, somente assim, poderá intervir na realidade com que trabalha e transformá-la. Com isso, inferimos que prática formativas que envolvam a Modelagem Matemática podem ser benéficas para o processo de ensino e aprendizagem.

\section{REFERÊNCIAS}

Barbosa, J. C. (2004). Modelagem Matemática. O que é ? Por que ? Como?

Veritati, n. 4 , p.73 - 80

Barreto, A. C. (1971). Tópicos de análise, Brasil, IMPA (Instituto de Matemática Pura e Aplicada) 
Bassanezi, R. C. (1994). Modelagem Matemática. Dynamis, Brasil. Blumenau, v. 2, n. 7, p. 55-83, abril/junho

Bassanezi, R. C. (1999). Modelagem Matemática: Uma disciplina emergente nos programas de formação de professores. Biomatemática IX. p.9-22

Bassanezi, R. C. (2002). Modelagem Matemática. Brasil. Editora Contexto

Biembengut, M. S. (1999). Modelagem Matemática \& Implicações no EnsinoAprendizagem de Matemática. Brasil, Blumenau, Editora da FURB

Booth, D. (1989). Transformation geometry concepts in children's spontaneous pattern painting in the primary school. In: BLUM, Werner; NISS, Mogens; HUNTLEY, lan (orgs.). Modelling, applications and applied problem solving: teaching mathematics in a real context. Chichester -Inglaterra, Ellis Horwood, p.70- 77

Bueno, S., Alencar, E.S., Gomes, H.C. (2016). O uso da Modelagem Matemática na Educação Básica. Anais do XII Encontro Nacional de Educação Matemática. Disponível em http://www.sbem.com.br/enem2016/anais/pdf/5538 2382 ID.pdf. Acesso em 01 fev. 2020

Burak, D., klüber, T. E. (2008). Educação Matemática: contribuições para a compreensão de sua natureza. In: Acta Scientiae, Brasil, (ULBRA), v. 10, p. 93 - 106, julho/dezembro

Carvalho, D. L., Miguel, A. Mendes, I. A. e brito, A. de J. (2009). História da Matemática em atividades didáticas. Brasil, $2^{\underline{a}}$ ed São Paulo: Editora Livraria da Física 


\section{Universidade Federal da Grande Dourados}

D’ambrosio, Ubiratan. (1986). Da realidade à ação — reflexões sobre educação e matemática. Brasil, São Paulo, SUMMUS/UNICAMP. 115p.

D’ambrosio, U. (1999). A história da matemática: questões historiográficas e políticas e reflexos na Educação Matemática. In: BICUDO, M. A. V.(org.). Pesquisa em Educação Matemática: concepções e perspectivas. Brasil, São Paulo: UNESP, p. 97-115.

Davis, P. J., hersh, R. (1986). A Experiência Matemática. Brasil, Rio de Janeiro, Francisco Alves

Ferreira, E. S. (1994). A importância do conhecimento etnomatemático Indígena na escola dos não-índios. Eni Aberto, Brasil, Brasília, ano 14, n. 62, abril/junho

Ferreira, D.H.L.; Wodewotzki, M.L.L. (2007). Questões ambientais e Modelagem Matemática: uma experiência com alunos do ensino fundamental. In: Barbosa, Jonei Cerqueira, Caldeira, Ademir Donizeti, Araujo, Jussara de Loiola.(orgs.). Modelagem Matemática na Educação Matemática Brasileira: Pesquisas e práticas educacionais. Recife, SBEM, p.115-132

Friedmann, C.V.P.;Lozano, A.G. (2007). Modelagem e modelos discretos: uma necessidade do ensino atual. In: Barbosa, Jonei Cerqueira, Caldeira, Ademir Donizeti, Araujo, Jussara de Loiola.(orgs.). Modelagem Matemática na Educação Matemática Brasileira: Pesquisas e práticas educacionais. Recife, SBEM, p.133-148

Gazzeta, M. A. (1989). Modelagem como estratégia de ensino da Matemática em cursos de aperfeiçoamento de professores. Dissertação (Mestrado em 


\section{Universidade Federal da Grande Dourados}

Educação) - Instituto de Geociências e Ciências Exatas - UNESP. Brasil, Rio Claro

Grandsard, F.; Schatteman, A. (1989). Problem solving for first year university students In: BLUM, Werner; NISS, Mogens; HUNTLEY, lan (orgs.). Modelling, applications and applied problem solving: teaching mathematics in a real context. Chichester -Inglaterra, Ellis Horwood, p.177-183

Herminio, M. H. G., Borba, M. C. (2010). A noção de interesse em projetos de modelagem Matemática, Revista: Educação Matemática e Pesquisa, Programa de Estudos Pós-Graduados em Educação Matemática da Pontifícia Universidade Católica de São Paulo, Brasil, São Paulo, v. 12, n.1, p.111-127

Malheiros, A. P. S. (2008). Educação Matemática online: a elaboração de projetos de Modelagem Matemática. Tese (Doutorado em Educação Matemática) Instituto de Geociências e Ciências Exatas (IGCE), Universidade Estadual Paulista (UNESP), Brasil, Rio Claro - São Paulo

Maturana, H. R., Varela, F. G. (1999). A Árvore do Conhecimento, tradução de Jonas Pereira dos Santos. Editora Psy II: Brasil, Campinas

Ponte, J.P. (199). Matemática: Uma disciplina condenada ao insucesso? Portugal Universidade de Lisboa

Toledo, E. C. V., Meyer J. F. C. A., Filho, R. B. (2005). Modelagem Dinâmica de um reator de Hidrotratamento. 3ํㅡㄹ Congresso Brasileiro de P\&D em petróleo e gás. Brasil, Salvador, Bahia. Disponível em 
http://www.portalabpg.org.br/PDPetro/3/trabalhos/IBP0186 05.pdf Acesso em 01 fev. 2020

Tortola, E. (2012). Os usos da linguagem em atividades de modelagem Matemática nos anos iniciais do ensino fundamental.Dissertação (Mestrado em Ensino de Ciências e Matemática) - Universidade Estadual de Londrina, Brasil, Londrina

Kotler, P., \& Keller, K. L. (2005). Administração de marketing (12a ed.). São Paulo: Prentice Hall.

Lima, E. C. P. (1997). Privatização e desempenho econômico: teoria e evidência empírica [Texto para discussão, № 532]. Brasília, DF: IPEA.

Ministério do Desenvolvimento, Indústria e Comércio Exterior. (n.d.). Ações setoriais para o aumento da competitividade da indústria brasileira. Recuperado em 19 de setembro, 2007 de http://www2.desenvolvimento.gov.br/sitio/publicacoes/desProducao/desPr oducao.php Acesso em 01 fev. 2020

Sant'ana, M.F. (2007). Modelagem de experimento e ensino de Cálculo. In: Barbosa, Jonei Cerqueira, Caldeira, Ademir Donizeti, Araujo, Jussara de Loiola.(orgs.). Modelagem Matemática na Educação Matemática Brasileira: Pesquisas e práticas educacionais. Recife, SBEM, p.149-160

Segatto-Mendes, A. P. (2001). Teoria de agência aplicada à análise de relações entre os participantes dos processos de cooperação tecnológica universidadeempresa (Tese de doutorado). Universidade de São Paulo, São Paulo, SP, Brasil. Recuperado de 


\section{Universidade Federal da Grande Dourados}

http://www.teses.usp.br/teses/disponiveis/12/12139/tde-24012002-114443

Acesso em 01 fev. 2020

Silva, A. B., \& Pereira, A. A. (2004, setembro). Fatores de influência na gestão das empresas de pequeno e médio porte da grande Florianópolis/SC. Anais do Encontro Nacional da Associação Nacional de Pós-Graduação e Pesquisa em Administração, Curitiba, PR, Brasil, 28.

Silva, M.N. (2009). Modelagem Matemática na formação continuada: análise das concepções de professores em um curso de especialização. Mestrado em Educação Matemática. Programa de Estudos Pós-graduados em Educação Matemática da Pontifícia Universidade Católica de São Paulo PUC/SP, Brasil, São Paulo

Tanure, B., Evans P., Cançado, V. L. (2010). As quatro faces de RH: analisando a performance da gestão de Recursos Humanos em empresas no Brasil. Revista de Administração Contemporânea, 14(4), 594-614. Recuperado de http://www.anpad.org.br/periodicos/arq pdf/a 1074.pdf. Acesso em 01 fev. 2020

Wittgenstein, L. (1980). Remarks on the philosophy of psychology (RPP, 1). Oxford: Blackwell

Wittgenstein, L. (2012). Investigações Filosóficas. 7. ed. Tradução de Marcos G. Montagnoli. Petrópolis: Editora Vozes; Bragança Paulista: Editora Universitária São Francisco, Brasil. 350 p. Tradução de: Philosophische Untersuchungen. 